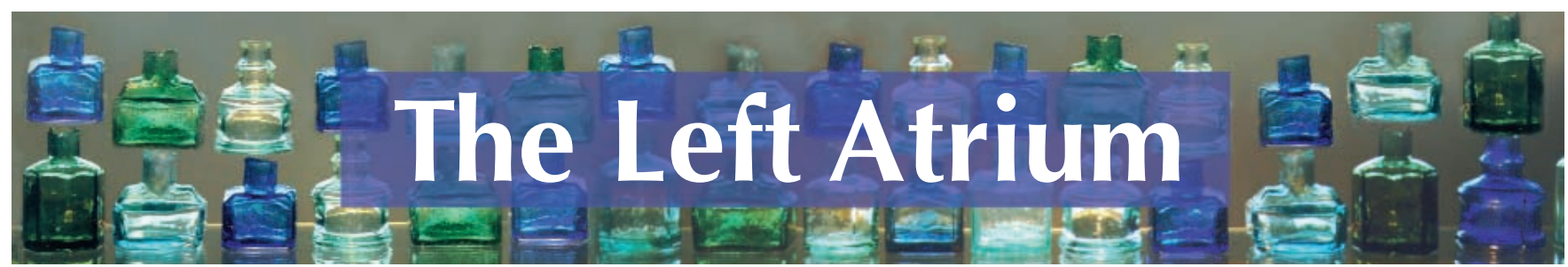

\section{The medicine is in the message}

Cultural sutures: medicine and media

Lester D. Friedman, editor

Durham (NC): Duke University Press; 2004

452 pp US\$24.95 (paper) ISBN 0-8223-3294-9

G iven the overwhelming impact of the "media age," it is perhaps surprising that a collection of this sort has not appeared before. Certainly, the editor's brisk introduction to an intriguing selection of topics makes a good case for the need to pay attention to the interconnections between medicine and the media. For example, the impact of popular media on the reception of research findings by scholarly and lay audiences is a genuine concern in need of thought. I'm less convinced by Friedman's claim that this volume constitutes an "interdisciplinary series" of papers. In contemporary scholarship, "interdisciplinarity" is a claim whose overambition is becoming as familiar as its overuse. It implies an understanding among contributors and a reflection upon one another' offerings; neither is found here. A plurality of disciplines is of course valuably represented, but they parade one after the other rather than performing in consort, as is so often the case in collections of this sort.

That being said, these essays are sensibly organized into sections pertaining to specific genres: print media, television, advertising, computers, the Internet, film, and so on. It would be impossible in a single volume to give a compendious treatment of such an array. What we have instead are marshalled vignettes, or perhaps the lifting of an ordered series of lids, which (despite the claim of "interdisciplinarity") can be read independently and in any sequence. The editor aims to "provide multiple points of access to, and comprehension of" what he terms "a broad range of subtle and overt interconnections between medicine and the media." I think he succeeds with respect to "access," but the level of understanding to be gained varies from chapter to chapter. For instance, Lucy Fischer's very readable commentary on the film The Doctor is a mixture of well-observed insights into the film's dynamics and of rather stilted and sometimes stale analyses of doctors' training, the paucity of narrative skills and gender issues. She is not mistaken; but we scarcely need these particular lessons de novo. On the other hand, fans of the film (I am among them) will enjoy Fischer's dissection of it.

A chapter by Arthur Caplan and Joseph Turow features a closely argued but rather dry analysis of print media coverage of euthanasia and end-of-life policy issues around the time of the televised "killing" of a patient by Dr Kevorkian. The authors' gloomy conclusion, that high-profile "zealots" distract the media from policy issues (which already suffer from a low base rate of attention) and toward crime and personality issues, is offered to us as though it should come as a surprise. A painstaking analysis is presented in support of this prosaic conclusion, offering methodical confirmation of what, to be candid, most observers would have taken for granted.

This problem of tameness afflicts other chapters, among them an earnest but (ironically) pedestrian review of drive-by advertisements for managed care organizations. Norbert Goldfield's discussion thereby exhibits another toopervasive problem for the reader: authors who are trying too hard to make much out of rather little. It's not that there is anything amiss with the conclusions reached; the trouble is that those conclusions do not gain conviction, still less ornamentation, from the stolid but inflated (and regrettably sometimes style-free) prose inflicted on us en route. Where this problem is at all pervasive, it leaves the reader with the sense that parts of the book may constitute academic solutions in search of a problem.

Elsewhere the book tantalizes only to infuriate. I will consider Sander Gilman's chapter on obesity in slightly more detail because of its vivid capacity to do both. An arresting beginning that contests the norms by which obesity is categorized among disabilities is followed by an unconvincing discussion of the fictional type of the fat detective as a specific "antithesis" of the lean and hungry thinker. But why this antithesis, and on what grounds? There follows a series of unargued assertions about the supposedly "feminine" (and hence "intuitive" and "empathic" and "vulnerable") character traits of the fat detective contrasted with his ratiocinating thin counterpart. This is frankly dubious both as stereotyping and as a complex in itself, and is certainly in need of substantial argument. Matters are worsened by claims that fat detectives "appear to think through their bodies," a strikingly unsupported statement leading to " $[t]$ he model of the primitive body that thinks." At times it is not easy for the uninitiated reader to distinguish Gilman's discourse from stream of consciousness; if there is indeed a "powerful cultural commonplace" associated with the "giant, hulking, primitive body" it is hard to see that it has anything to do with empathy or intuition, and still less that the fat detective thinks well because of his bulk, or that he is the "ultimate new man."

As against this, Therese Jones' initially perplexing comparison between the beating of Rodney King and the inexorable treatment of burn victim Dax Cowart - alleging both to be instances of "political torture" inasmuch as they defied the ostensible purposes of the agencies involved (law enforcement, health care) - did manage to survive this reader's initial scepticism. This chapter is a steady working through of familiar and generally credible arguments against the presumptive "innocence" of documen- 
tary film which, just like fiction, must necessarily be constructed toward the filmmaker's ends. The comparative premise apart, there are no real surprises, but the case is made effectively - with occasional and, one feels, appropriate hints of anger. Unfortunately, the second of two documentaries on Cowart receives only a fraction of the analytic attention of the first, and it would have been interesting to see Jones' program carried through a little more completely.

Despite its unnecessarily jargonridden opening, Johnathan Metzl's re-assessment of critiques of advertising that proceed from gender theory begins with a welcome willingness to complicate the too-simple assumptions made by some of the authors he considers. There follows an interesting tale of the replacement, within a series of pharmaceutical advertisements over time, of images of the authoritative (and male) physician's gaze with images of the pharmaceutical products themselves. Readers will judge for themselves how persuasive Metzl's recruitment of psychoanalytic concepts is in his analysis of this transition, but they can hardly fail to be intrigued.

In one of the book's stronger chapters Marc Cohen and Audrey Shafer succinctly trace a broad history of the emergence and dominance of scientific medicine through visual representations of doctors in painting, photography and, latterly, television. Their thoughtful choice of images, equally thoughtfully discussed, makes their points effectively and injects fresh interest and insight into a conventional historical synopsis.

In summary, Cultural Sutures is a slightly baffling mix of the enjoyable and the arcane, a project that perhaps seemed more inevitable to its editor than it does to the uncommitted reader. Lacking a clear role - too patchy for a reference work, yet too laboured for a popular invitation - it may nonetheless encourage others to pay sustained attention to the culturally important and increasingly synergistic relations between medicine and the media.

\section{H.M. Evans}

Professor of Humanities in Medicine

University of Durham

Durham, UK

\section{Room for a view}

\section{The drop attack}

$\mathrm{T}$ he nurse's voice at the other end of the phone contained some urgency. "You'd better come right back to the OR, Dr. Bernstein, the guys need you. We have a situation."

What could it possibly be? It was the last day of work before a much-needed summer holiday, and I had a worsethan-usual backlog of urgent brain tumour cases. The operating room manager had kindly found me some extra time on this particular Friday. So the last surgical patient before my vacation was a lovely 60 -year-old lady who had severe headaches and weakness caused by a large brain tumour.

The actual surgery for removal of her rather bloody, delicately located tumour went very well; my residents and I were quite happy with the job. I left the OR for my trainees to close the patient; in our teaching hospital this was the norm. They were both excellent residents - talented doctors and good surgeons who were conscientious to a fault.

I returned to the OR within minutes. It was eerily quiet. Two young students who had been intently observing the surgery were now sitting qui-

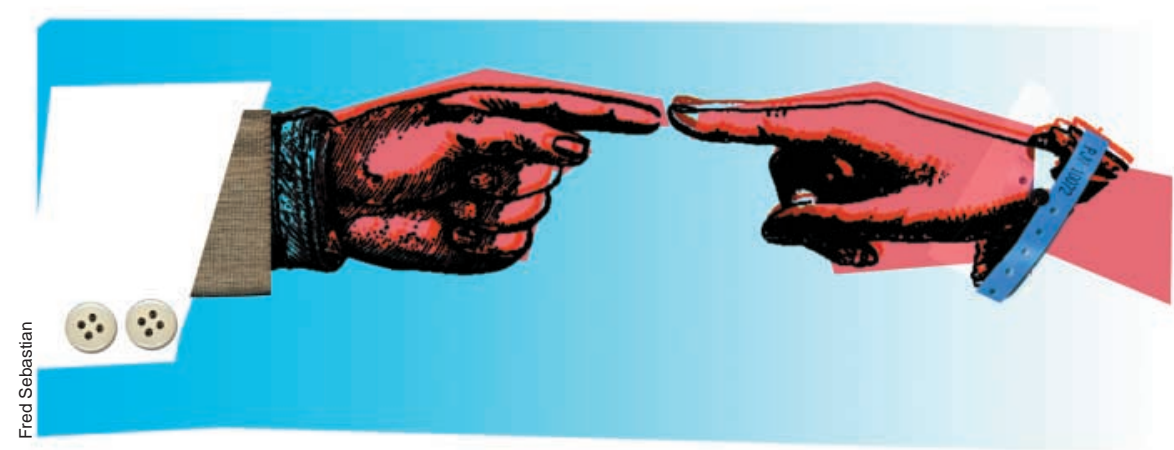

etly. The anesthetist avoided my gaze as I passed her. I approached the operating table, and the senior resident explained the situation with a forced calmness. The bone flap we had opened to expose and remove the tumour had been dropped on the floor. It was about the size of a playing card. The junior resident was preparing it with little plates and screws for reattachment to the skull when it slithered out of his hands. This good-natured young man was mortified. He didn't speak. His gaze was fixed on the patient's head.

Fumbles of this kind are an uncommon but well-recognized mistake in surgery; this was my second personal experience with a dropped bone flap in a 20-year career in which I have performed many thousands of surgeries. The senior resident rattled off the therapeutic options in his typically thorough fashion. In the old days we used to "cook" a contaminated bone flap in the autoclave, the same "oven" used to sterilize surgical instruments. But this practice was no longer acceptable to the infection control experts at my hospital. So we decided to fill the skull defect with metal mesh and surgical epoxy, materials made just for such a purpose. Thirty minutes later, final cosmetic touches with a high-speed drill had produced a beautifully contoured skull that was also harder than rock. The residents then closed the scalp. A turban-style head dressing was applied by the junior resident, and the patient immediately awoke in the OR, neurologically intact and speaking well.

I gathered the residents and students 